\title{
Advanced Process Control to Minimize Disturbance in Gas Processing Facility (GPF)
}

\author{
Safira Firdaus Mujiyanti* and Totok Ruki Biyanto \\ Department of Engineering Physics, Institut Teknologi Sepuluh Nopember, Sukolilo, \\ Jl. Teknik Kimia, Sukolio, Surabaya 60111, Indonesia
}

\begin{abstract}
For the gas treatment process, the process that occurs is separating the gas from the components of $\mathrm{H}_{2} \mathrm{~S}, \mathrm{CO}_{2}$, and $\mathrm{H}_{2} \mathrm{O}$. The separation of gases from these components uses the aid of Amine fluid and TEG fluid. The unit that important in this process are Amine and TEG Contactor. To be able to separate the three components from the gas, the mass flow rate of Amine and TEG must be controlled so that the processing can work optimally. In reality in the field, the input of this process from the well is not always steady. So, this condition becomes a disturbance from the control process. The solution to minimize the disturbance of process with Advanced Process Control (APC). Therefore, this research will design APC on Amine and TEG Contactor to improve the stability of the mass flow response of Amine and TEG. In designing APC, the plant model is required first. Plant modelling obtained with software HYSYS and validated with MATLAB. The result shows the RMSE value below $5 \%$. The result proved to be able to make the process more stable from before design proven by slurries settling time, steadystate errors and maximum overshoot.
\end{abstract}

Keywords: Control strategy, contactor, modelling,

\section{Introduction}

Natural gas is the most efficient energy in terms of its use [1]. There are several processes before gas can be used, such us production, purification, separation and distribution. The purification process is a step to separate gases from harmful components such as $\mathrm{H}_{2} \mathrm{~S}, \mathrm{CO}_{2}$ and $\mathrm{H}_{2} \mathrm{O}$. The plant that used to do purification process is also commonly known as the Gas Processing Facility (GPF). There are two units that are responsible for the separation of the components of the gas, namely Amine Contactor and TEG Contactor. Amine Contactor is tasked to separate the $\mathrm{H}_{2} \mathrm{~S}$ and $\mathrm{CO}_{2}$ components used Amine liquid until it does not exceed the allowable standard limit [2]. There is a maximum standard limit allowed for $\mathrm{CO}_{2}$ which is $1 \mathrm{~mol} \%$ and the $\mathrm{H}_{2} \mathrm{~S}$ is $4 \mathrm{ppm}$ [3]. While TEG Contactor is tasked to separate $\mathrm{H}_{2} \mathrm{O}$ components from natural gas used TEG liquid, it does not exceed the standard limit [4]. The water content standard limit is $7 \mathrm{lb} \mathrm{MMSCF}^{-1}$ for US piping Systems, $4 \mathrm{lb} \mathrm{MMSCF}^{-1}$ for the Canadian piping system, as well as $1 \mathrm{lb} \mathrm{MMSCF}^{-1}$ to $2 \mathrm{lb} \mathrm{MMSCF}^{-1}$ for the Alaska environmental piping system [5].

\footnotetext{
* Corresponding author: $\underline{\text { safirafirdaus.f49@gmail.com }}$
} 
Various research on GPF has been done for the process to proceed optimally. Starting from propose mathematical model [6] and optimization of contactor design [7]. But the proposed research is only able to the problem in a static state. In its application in the field, the optimal condition needed must be in a dynamic condition, which is the condition of the plant that changes to time. So ever proposed plant controllers on the $\mathrm{CO}_{2}$ Capture section [8]. The $\mathrm{CO}_{2}$ capture process also uses liquid aid. However, there are things that have not been noticed in these conditions that can become disturbance at the liquid flow rate used to bind the components in the gas. It is a gas production of a well, which affects the mass flow rate of the liquid component binding.

A small change in gas inputs can cause a large change in the mass flow rate of liquid. Changes in values that do not match a set point may result in the process of splitting the harmful components of the gas from running optimally. The effect can result in the quality of the gas output is not good. So, this research will propose an advanced process Control (APC) in gas processing to reduce the disturbance of plant. The APC used is feedforward control, as it has been proven that feedforward control is capable of predicting the disturbance that will occur in the plant [9]. With the prediction that has been done, the stability of the plant will be better. To be able to design the APC, plant model is required using FOPDT. It is evident that FOPDT models are one of the easiest and simplest modelling to apply [10]. However, the difficulty in this is to get a model that corresponds to a dynamic state in the field. Because for the plant that has been running, the data known is only plant properties. So, the novelty in this research is able to propose the APC design in GPF with FOPDT model obtained from plant properties to reduce the disturbance of plant.

\section{Method}

\subsection{Gas Processing Facility (GPF) plant model}

The unit that important in gas processing are Amine and TEG Contactor. Amine and TEG Contactor is a type of absorber. Absorber is an operating unit in the oil industry that serves to perform the absorption or absorption process. The absorber working system is the incoming gas (gas in) through the lower inlet while the liquid or commonly known as liquid in through the upper inlet. Then there will be contact between the gas and the liquid, so that the components that want to be separated from the gas will be bound to the solvent and carried out through the outlet of the bottom (liquid out). These components can be bound by liquids due to chemical reactions in them. Chemical reactions that occur based on the type of process in the plant. Meanwhile, the clean gas will go to the top outlet (gas out). This process occurs based on the principle of density. That a gas that has a lighter density will go towards the top, whereas a liquid that has a heavier density will go down.

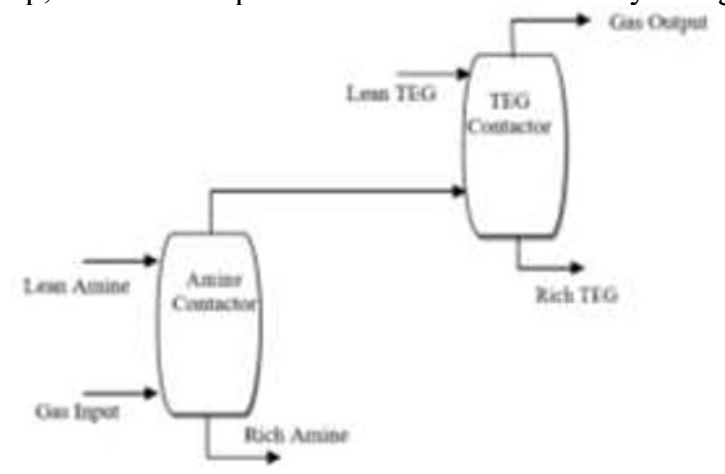

Fig. 1. Amine and TEG process. 


\subsection{FOPDT process model}

The dynamic system of industrial processes can be modelled with FOPDT (First Order Plus Dead Time) transfer function. FOPDT is obtained from conducting an open loop test so that there will be a chart of the order response one in Figure 2 as follow.

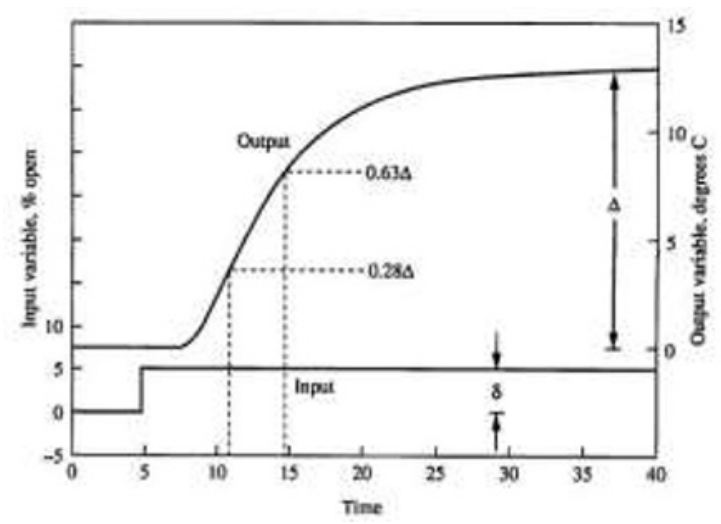

Fig. 2. System respons graph [11].

From the system response graph in Figure 2, the FOPDT transfer function will be obtained in the Equation (1) as follows [11]:

$$
G(s)=\frac{K e^{-\theta s}}{\tau s+1}
$$

$\mathrm{K}$ value will be obtained in Equation (2), $\tau$ value in Equation (3), and $\theta$ value in Equation (4) as shown bellows.

$$
\begin{aligned}
& K=\frac{\Delta}{\delta}=\frac{\Delta \text { Process Variable }}{\Delta \text { Manipulated Variable }} \\
& \tau=1.5\left(t_{63 \%}-t_{28 \%}\right) \\
& \theta=t_{63 \%}-\tau
\end{aligned}
$$

Where:

$$
\begin{array}{ll}
\mathrm{K} & : \text { Gain } \\
\tau & : \text { Time Constant } \\
\theta & : \text { Dead Time } \\
\mathrm{t}_{63 \%} & : \text { Time for } 63 \% \text { of Output } \\
\mathrm{t}_{28 \%} & : \text { Time for } 28 \% \text { of Output }
\end{array}
$$

\subsubsection{Lean amine mass flow model}

Process model for Lean Amine mass flow rate is achieved by conducting an open loop test. An open loop test is done by giving the input a step signal. In the model of Lean Amine mass flow, the input of this process is the opening of the control valve, with increase $5 \%$ of control valve. The test response result of the mass flow rate of Lean Amine is shown in Figure 3. 


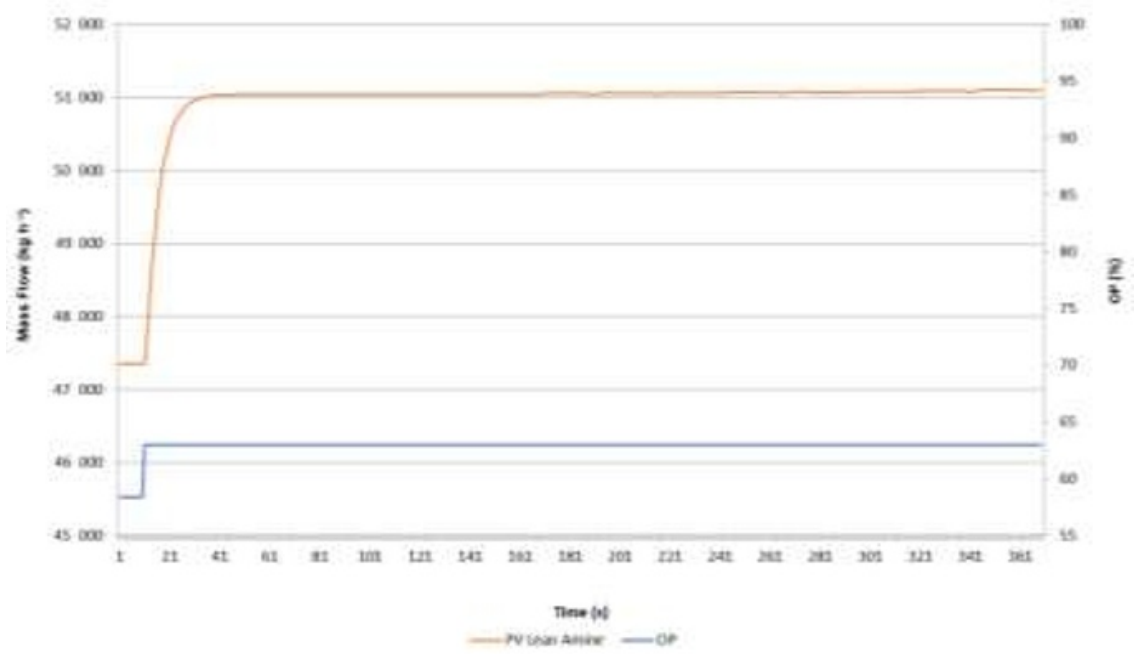

Fig. 3. Lean amine open loop test response

Response from Figure 3 show that Lean Amine Mass Flow FOPDT model obtained in Equation (5) as shown bellows.

$$
G_{p}(s)=\frac{811.69 e^{-1.67 s}}{5.27 s+1}
$$

\subsubsection{Lean TEG mass flow model}

Process model for Lean TEG mass flow rate is achieved by conducting an open loop test. An open loop test is done by giving the input a step signal. In the model of Lean TEG mass flow, the input of this process is the opening of the control valve, with increase $5 \%$ of control valve. The test response result of the mass flow rate of Lean TEG is shown in Figure 4.

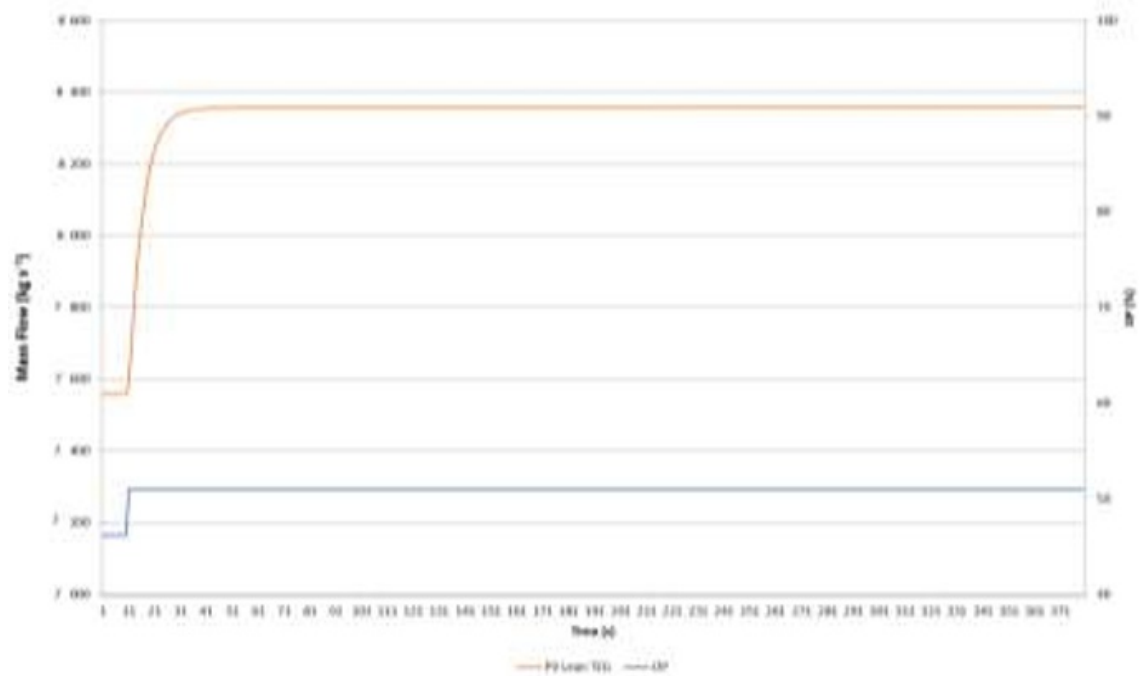

Fig. 4. Lean TEG open loop test response. 
Response from Figure 4 show that Lean TEG Mass Flow FOPDT model obtained in Equation (6) as shown bellows.

$$
G_{p}(s)=\frac{164.57 e^{-1.16 s}}{5.24 s+1}
$$

\subsubsection{Lean amine mass flow disturbance model}

Process model for disturbance of Lean Amine mass flow rate is achieved by conducting an open loop test. A disturbance open loop test is done by giving the input a step signal. In the model of Lean Amine mass flow disturbance, the input of this process is the opening of the disturbance control valve, with increase $5 \%$ of control valve. The disturbance of this process is gas input or feed mass flow. The test response result of the mass flow rate of Lean Amine is shown in Figure 5.

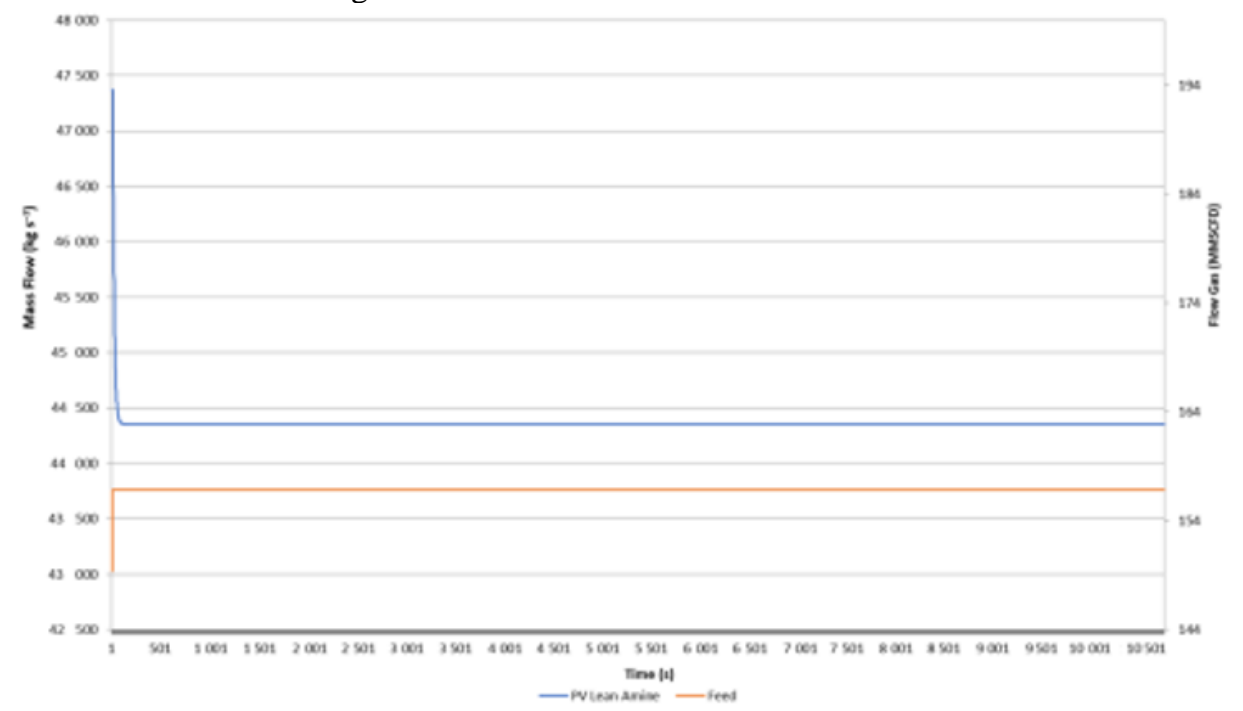

Fig. 5. Lean Amine disturbance open loop test response.

Response from Figure 5 show that Lean Amine mass flow disturbance FOPDT model obtained in Equation (7) as shown bellows.

$$
G_{d}(s)=\frac{-403.64 e^{-1.81 s}}{3.04 s+1}
$$

\subsubsection{Lean TEG mass flow disturbance model}

Process model for disturbance of Lean TEG mass flow rate is achieved by conducting an open loop test. A disturbance open loop test is done by giving the input a step signal. In the model of Lean TEG mass flow disturbance, the input of this process is the opening of the disturbance control valve, with increase $5 \%$ of control valve. The disturbance of this process is gas input mass flow. The test response result of the mass flow rate of Lean TEG is shown in Figure 6. 


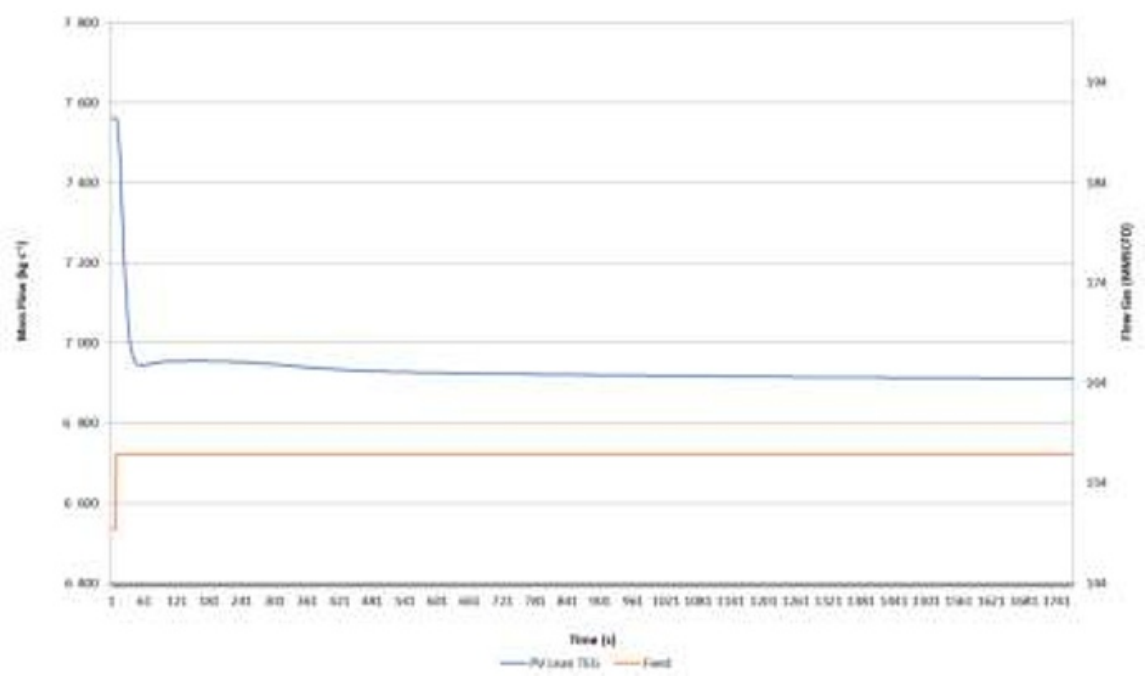

Fig. 6. Lean TEG disturbance open loop test response

Response from Figure 6 show that Lean TEG mass flow disturbance FOPDT model obtained in Equation (8) as shown bellows.

$$
G_{d}(s)=\frac{-87.06 e^{-6.59 s}}{11.39 s+1}
$$

\subsection{Process model validation}

Process model validation is performed to test the FOPDT model results that have been obtained from the process data. Testing of FOPDT results is done using Simulink by giving a step signal on input model results FOPDT. Then the FOPDT test results compared to the process data. Then obtained the value of RMSE (Root Mean Square Error) as follows in Table 1 .

Table 1. FOPDT model validation

\begin{tabular}{|c|c|}
\hline FOPDT model & RMSE \\
\hline Lean amine mass flow & $0.52 \%$ \\
\hline Lean TEG mass flow & $0.56 \%$ \\
\hline Lean amine mass flow disturbance & $0.82 \%$ \\
\hline Lean TEG mass flow disturbance & $0.46 \%$ \\
\hline
\end{tabular}

From Table 1, the validation results of the FOPDT model already done. All of them showed RMSE results below $1 \%$, indicating that the FOPDT modelling obtained were properly tested and in accordance with the process data.

\subsection{Advanced Process Control (APC) for gas processing}

APC used for this process is feedforward control. he Feedforward controller is a controller that can provide information about any interference to the PID control. This controller can provide a warning in advance of indications of interference that will occur, so the Feedforward controller will signal to the actuator in order to adjust to the interference. Feedforward gain model will show in Equation (9) as follows [11]. 


$$
G_{f f}(s)=-\frac{G_{d}(s)}{G_{p}(s)}=K_{f f}\left(\frac{T_{l d} s+1}{T_{l g} s+1}\right) e^{-\theta_{f f} s}
$$

Where:

$\begin{array}{ll}\mathrm{K}_{\mathrm{ff}}=-\mathrm{K}_{\mathrm{d}} / \mathrm{K}_{\mathrm{p}} & : \text { Gain } \\ \theta_{\mathrm{ff}}=\theta_{\mathrm{d}}-\theta_{\mathrm{p}} & : \text { Dead time } \\ \mathrm{T}_{\mathrm{id}}=\tau_{\mathrm{p}} & : \text { Lead time } \\ \mathrm{T}_{\mathrm{ig}}=\tau_{\mathrm{d}} & : \text { Lag time }\end{array}$

Thus, the feedforward gain for disturbance of Lean Amine mass flow rate is on the Equation (10) as follows.

$$
G_{f f}(s)=-0.49\left(\frac{5.27 s+1}{3.04 s+1}\right) e^{-0.14 s}
$$

While the feedforward gain for disturbance of Lean TEG mass flow rate is on the Equation (11) as follows

$$
G_{f f}(s)=0.52\left(\frac{5.24 s+1}{11.39 s+1}\right) e^{-5.43 s}
$$

\section{Results and discussions}

Testing the system performance on Amine and TEG Contactor is provided by increase and decrease the flow rate of the feed by providing a step signal of $5 \%$. From the initially 149.4 MMSCFD, increased by $5 \%$ or about 7.47 MMSCFD to 156.87 MMSCFD and decreased to 141.93 MMSCFD. Then design of feedforward controllers on Amine and TEG Contactor will be compared with the control PID contained in the plant.

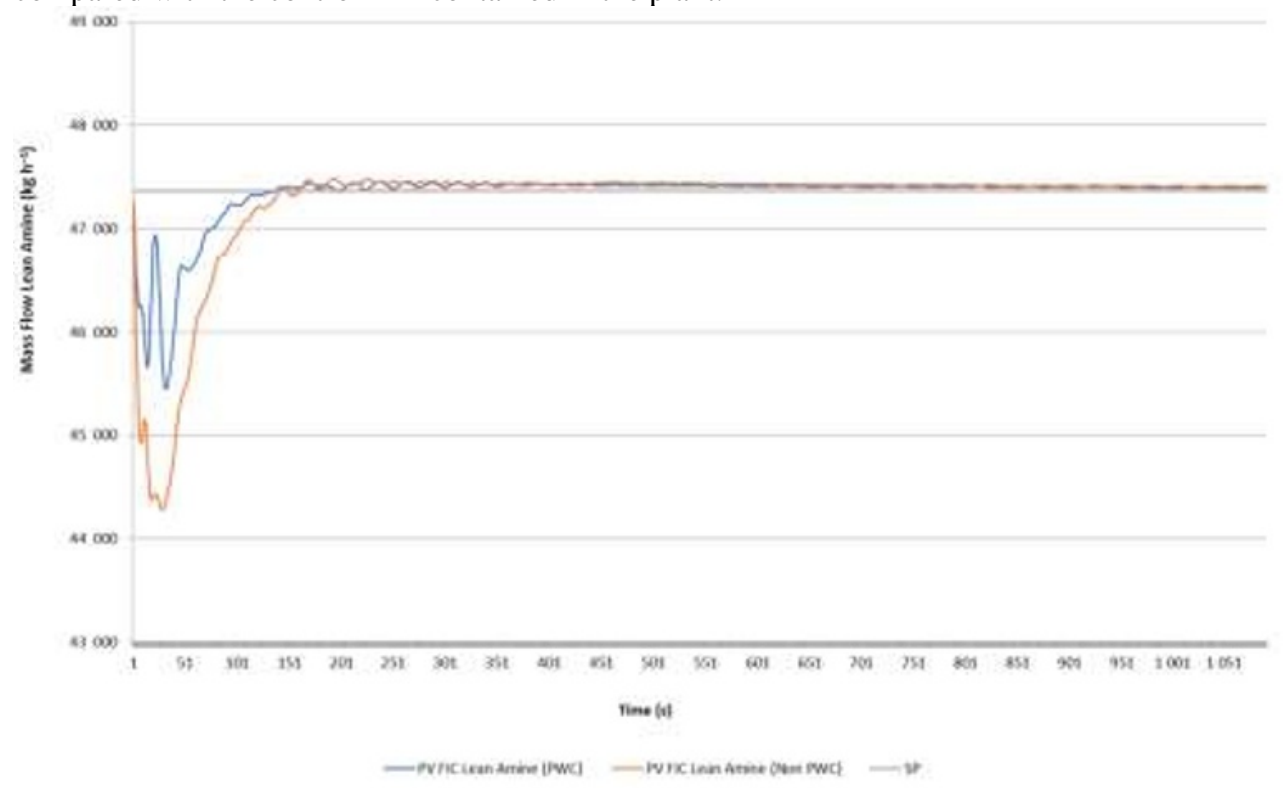

Fig. 7. Lean Amine mass flow rate response at increase $5 \%$ of disturbance 
Figure 7 The following is a graph of the system's response due to the disturbance given by the Lean Amine mass flow rate plant when the feed is increased by $5 \%$. Response characteristic from Figure 7 will show in Table 2 as follows.

Table 2. Lean Amine mass flow rate response characteristics at increase $5 \%$ of disturbance

\begin{tabular}{|c|c|c|}
\hline Response characteristic & PID & APC \\
\hline Maximum overshoot (\%) & 6.521 & 4.054 \\
\hline Steady state error (\%) & 0.002 & 0.000 \\
\hline Settling time (s) & 161 & 138 \\
\hline
\end{tabular}

Figure 8 bellows will show system response graph due to the disturbance given by the Lean Amine mass flow rate plant when the feed is increased by $5 \%$.

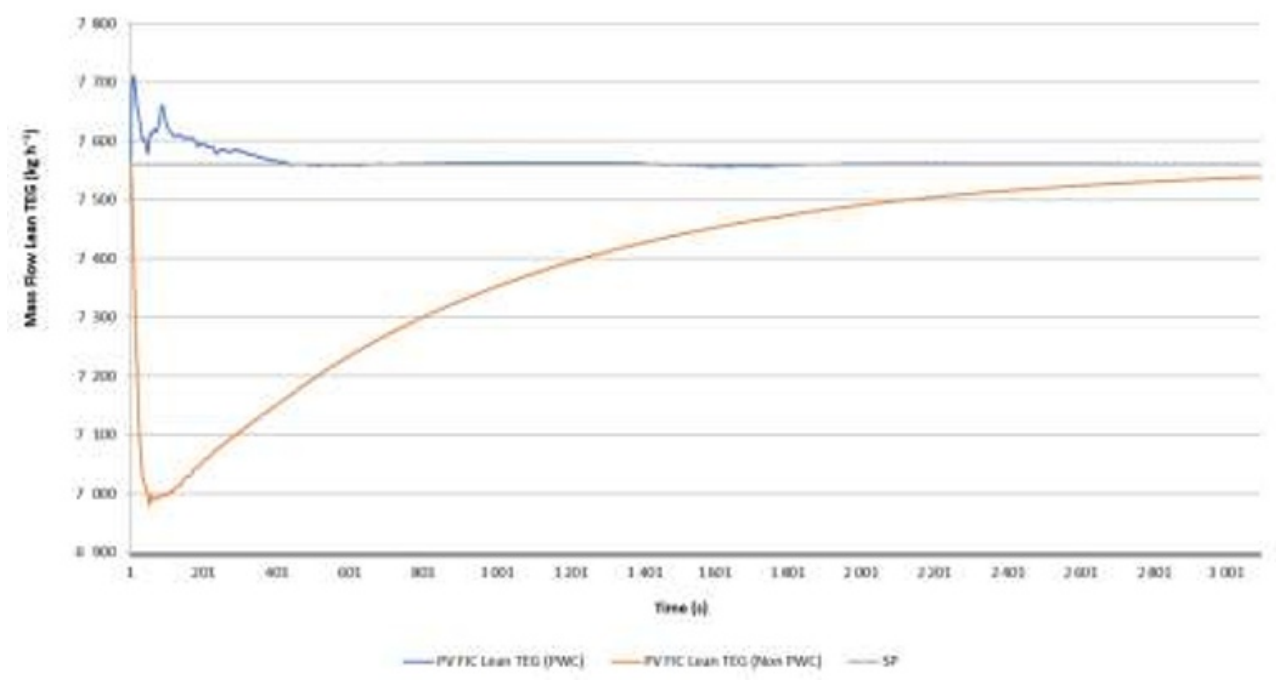

Fig. 8. Lean TEG mass flow rate response at increase $5 \%$ of disturbance

Response characteristic from Figure 8 will show in Table 3 as follows.

Table 3. Lean TEG mass flow rate response characteristics at increase $5 \%$ of disturbance

\begin{tabular}{|c|c|c|}
\hline Response characteristic & PID & APC \\
\hline Maximum overshoot (\%) & 6.521 & 1.996 \\
\hline Steady state error (\%) & 0.284 & 0.000 \\
\hline Settling time (s) & 2971 & 2130 \\
\hline
\end{tabular}

When the feed is increased by $5 \%$, the impact of the process is that the pressure on Amine Contactor will increase. In the event of increased pressure on Amine Contactor, a pressure drop on the inlet lean Amine will decrease. This pressure drop will cause in decreased flow rate of lean amine mass which would go into Amine Contactor. So that the response given to the PID handler at the time of the feed value change is a decrease response and oscillation occurs. Meanwhile, to overcome the sudden change in the flow rate of bait that becomes impaired at the flow rate of Lean Amine and Lean TEG then added feedforward design method. The result of testing performance due the decreasing feed $5 \%$ for Lean Amine will show in Figure 9 as shown follows. 


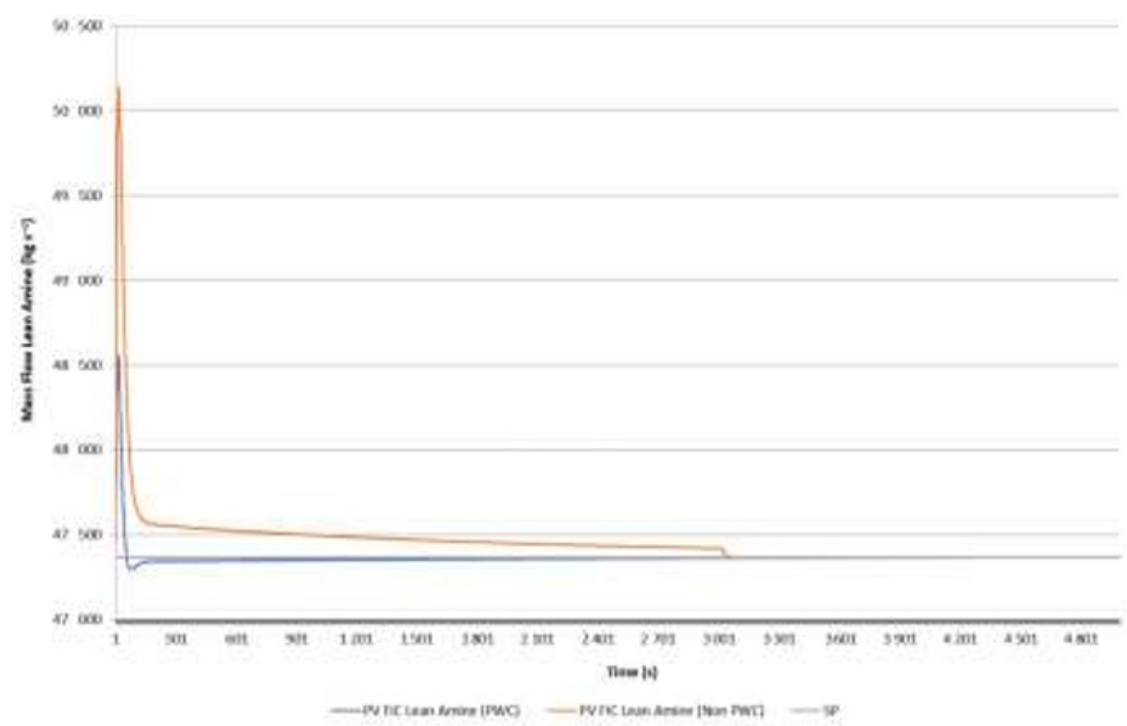

Fig. 9. Lean Amine mass flow rate response at decrease $5 \%$ of disturbance

Response characteristic from Figure 9 will show in Table 4 as follows.

Table 4. Lean Amine mass flow rate response characteristics at decrease $5 \%$ of disturbance

\begin{tabular}{|c|c|c|}
\hline Response characteristic & PID & APC \\
\hline Maximum overshoot (\%) & 5.858 & 2.504 \\
\hline Steady state error (\%) & 0.010 & 0.000 \\
\hline Settling time (s) & 3365 & 3043 \\
\hline
\end{tabular}

Figure 10 bellows will show system response graph due to the disturbance given by the Lean TEG mass flow rate plant when the feed is decreased by $5 \%$.

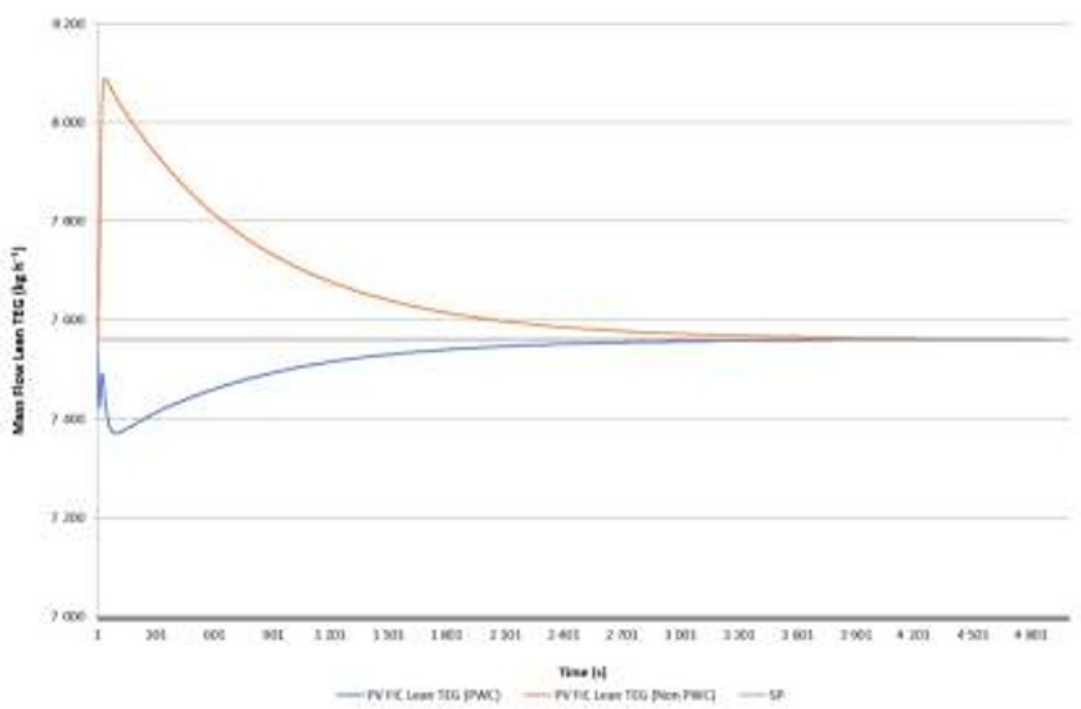

Fig. 10. Lean TEG mass flow rate response at decrease $5 \%$ of disturbance 
Response characteristic from Figure 10 will show in Table 5 as follows.

Table 5. Lean TEG mass flow rate response characteristics at decrease $5 \%$ of disturbance

\begin{tabular}{|c|c|c|}
\hline Response characteristic & PID & APC \\
\hline Maximum overshoot $(\%)$ & 7.002 & 2.508 \\
\hline Steady state error (\%) & 0.010 & 0.000 \\
\hline Settling time (s) & 5159 & 4848 \\
\hline
\end{tabular}

When the feed is decreased by $5 \%$, the impact of the process is that the pressure on Amine Contactor will decline. If a pressure drop occurs in Amine Contactor, then a pressure drop on the inlet lean Amine will increase. This increased pressure dropped resulted in an increase in the flow rate of lean amine mass that would go into Amine Contactor. So that the response given to the PID controller at the time of change in the bait value is an increase in response or in other words Lean Amine that enters the plant more and more. Thus, due to the addition of Feedforward controllers on Amine and TEG Contactor. From the test of interference given, it was obtained that the response characteristic produced by the advanced process control structure was able to eliminate steady state errors, to minimize overshoot and to accelerate settling time.

\section{Conclusion}

The conclusion of the study was that FOPDT modeling testing for advanced process control processes on Gas Processing has been properly tested for the RMSE value obtained below 1 $\%$. The RSME value for the FOPDT modelling test of Lean Amine mass flow rate was 0.52 $\%$ and for the Lean TEG flow rate of $0.56 \%$. On the other hand, the added advanced process control of Gas Processing is able to produce a more stable system response than the only PID controller when it is impaired in the form of changing feed flow rate. This is demonstrated by decreased settling time and maximum overshoot as well as loss of steadystate errors. So, advanced process control in Gas Processing proved to minimize the presence of disturbance in this plant.

\section{References}

1. M.A. Qyyum, Y.D. Chaniago, W. Ali, K. Qadeer, M. Lee, J. Clean. Prod. 211:574589(2019).

https://doi.org/10.1016/j.jclepro.2018.11.233

2. T. Nguyen, M. Hilliard, G. Rochelle, Energy Procedia 4:1624-1630(2011). https://doi.org/10.1016/j.egypro.2011.02.033

3. T.N.G. Borhani, M. Afkhamipour, A. Azarpour, S.H. Emadi, V. Akbari, J. Ind. Eng. Chem. 34:344-355(2016). https://doi.org/10.1016/j.jiec.2015.12.003

4. M. Neagu, D.L. Cursaru, J. Nat. Gas Sci. Eng. 37:327-340(2017). https://doi.org/10.1016/j.jngse.2016.11.052

5. S. Mokhatab, W.A. Poe, J.Y. Mak, Natural Gas Transmission and Processing, Oxford, UK: Gulf Professional Publihing (2019), p. 181-262.

https://doi.org/10.1016/C2010-0-66115-3

6. R. Chebbi, M. Qasim, N.A. Jabbar, Energy Reports 5:723-732(2019). https://doi.org/10.1016/j.egyr.2019.06.014 
7. H.M. Kvamsdal, M. Hillestad, Int. J. Greenh. Gas Control, 11:11-20(2012).

https://doi.org/10.1016/j.ijggc.2012.07.013

8. Y. Lin, T. Pan, D.S. Wong, S. Jang, Ind. Eng. Chem. Res. 50,3:5067-5072(2011). https://doi.org/10.1021/ie100771x

9. H. Kim, E.K. Kim, J. Kim, K.S. Lee, S. Kim, Y. Han, Int. J. Electr. Power Energy Syst.,71:351-357(2015).

https://doi.org/10.1016/j.ijepes.2015.03.022

10. J. Cvejn, J. Process Control 19,9:1486-1495(2009).

https://doi.org/10.1016/j.jprocont.2009.07.002

11. T. Marlin, Process Control Designing Processes and Control Systems for Dynamic Performance, 2nd Edition, McMaster University (2012).

http://pc-textbook.mcmaster.ca/ 